\title{
O corpo docente frente às políticas de educação prioritária na França: formação, entrada no trabalho e trajetórias profissionais $^{1}$
}

\section{The teaching staff and compensatory education policies in France: Teaching education, early carrer and professional trajectories}

\author{
Maíra de Araujo Mamede*
}

\begin{abstract}
RESUMO
Neste artigo, propomos, a partir de um estudo bibliográfico, uma discussão sobre as características do corpo docente na França, com foco nas políticas de formação e de entrada no ofício docente. Trataremos das especificidades do contexto francês, especialmente em relação a constituição do sistema de ensino, intimamente ligada à democratização, tanto no sentido pedagógico quanto político, para examinar melhor a maneira como elas intervêm na composição do corpo docente, na formação e no recrutamento atual. Efetivamente, as diferentes configurações da formação docente refletem as diferentes configurações do próprio sistema educativo. Essas políticas fazem com que, num jogo de transformações e continuidades, a formação atual se explique parcialmente através dos agenciamentos institucionais precedentes. Percebe-se que, apesar da unificação do sistema, por detrás da denominação Educação Nacional, o corpo docente seja pouco unificado de um ponto de vista sociológico, com variações ligadas tanto ao nível de ensino quanto ao contexto de exercício.
\end{abstract}

Palavras-chave: Políticas educacionais. Formação docente. Trabalho docente. Democratização.

1 Este trabalho foi feito dentro de uma pesquisa coletiva "Abordagens Comparadas a Políticas para Reduzir as Desigualdades Educacionais entre a França e a Argentina. Novos desafios para o estudo das desigualdades educacionais e educacionais", financiados pelo programa Ecos Sud.

*Université Paris-Est Créteil. Paris, França. E-mail: maira.mamede@u-pec.fr. https://orcid. org/0000-0003-1975-4518. 


\begin{abstract}
In this paper, we propose a bibliographic study of the characteristics of the teaching profession in France, related to teacher education policies and the ways beginners enter the profession. We discuss the specificities of the French context, particularly with regard to its constitution and the close relationship between school and democratization, both from a pedagogical and political point of view, in order to better examine how these specificities interferes in the composition of teachers as a social group, training and recruitment. Different configurations of teacher education seem to reflect the various configurations of the education system itself and in a game of transformations and continuities, the current teacher education is explained partially by previous institutional arrangements. It appears that, despite the unification of the system, under the banner of the National Education, the teaching body appears to be less unified from a sociological point of view, with variations related to both the level of education and the context of the exercise of the profession.
\end{abstract}

Keywords: Educational policy. Teacher education. Teaching. Democratization.

\title{
Introdução
}

Na França, a escolarização é realizada massivamente pela rede pública: em 2016, 86,3\% dos 6,8 milhões de alunos do primário ${ }^{2}$ foram escolarizados no sistema público, bem como 78,8\% dos 5,5 milhões de alunos do secundário $^{3}$ (MEN-DEPP, 2017). Os professores que trabalham na rede pública são majoritariamente recrutados por meio de concurso e, consequentemente, são funcionários do Estado Francês, em um sistema altamente centralizado (Fons \& Meyer, 2005). Todavia, a centralização das políticas de recrutamento não implica necessariamente homogeneidade do corpo docente. Pelo contrário, essas políticas, juntamente com outras características do sistema educativo francês, participam da constituição de um sistema altamente heterogêneo.

2 Correspondente à educação infantil e às séries iniciais do ensino fundamental no sistema brasileiro. 3 Correspondente às séries finais do ensino fundamental e ao ensino médio no sistema brasileiro. 


\section{A democratização escolar na Escola da República: homogeneidade ou heterogeneidade?}

O estatuto de funcionário público dos professores é historicamente explicado pelo papel fundador da "Escola da República”, uma instituição tanto política quanto pedagógica (Mougniotte, 1997). Essa expressão surge no final do século XIX com as leis de Jules Ferry, por meio das quais a educação primária se torna pública e gratuita (1881) e a instrução se torna laica e compulsória até os 13 anos (1882). A escola é acima de tudo uma instituição pública, componente fundamental da República Francesa, cujos valores e conhecimento ela deve disseminar. As leis de Ferry contribuem para a consolidação do Estado-nação francês igualmente no plano linguístico porque o francês se torna a única língua de instrução.

O movimento de democratização escolar que essas leis inauguram, no entanto, merece ser recontextualizado, porque a escolarização dos alunos é, então, feita em duas ordens paralelas de educação, primária e secundária, que não significam, portanto uma organização em níveis de ensino como atualmente. $\mathrm{O}$ sistema de ensino primário é caracterizado por uma escolaridade curta destinada às crianças das classes populares em escolas primárias de ensino fundamental, culminando em um certificado de estudos primários, após sete anos de escolaridade. A ordem do secundário era propedêutica para o ensino superior. Pago, o secundário educa crianças das classes mais favorecidas a partir de 6 anos nas petites classes de lycée até o baccalauréat, prova que finaliza o ensino médio, totalizando onze anos de escolaridade. A divisão entre estas duas ordens paralelas se reflete também na formação e no recrutamento de professores. Duas grandes diferenças devem ser enfatizadas: os professores da escola primária são treinados na École Normale, de nível secundário, e recrutados por um concurso acadêmico ${ }^{4}$, local; os professores do ensino médio tem formação disciplinar na universidade e são recrutados por concurso nacional (Lang, 1999).

A Escola Normal Primária é a via preferencial para os bons alunos de origem popular que desejam ampliar sua escolaridade, além do primário. $\mathrm{O}$ concurso é a porta de entrada, e antecede à formação, em sistema de internato. As Escolas Normais oferecem uma formação acadêmica e profissional (pedagógica) que dá acesso ao certificado de aptidão para o ensino fundamental e um cargo de instituteur ${ }^{5}$. A educação primária aparece, assim, como um circuito fechado,

4 O sistema de ensino é dividido em 30 Academias em função da divisão políticoadministrativa do país.

5 Instituteur (ou institutrice) é o termo utilizado para os professores do primário. Ele perdura até 1989 . 
capaz de se auto-alimentar, equilíbrio que será quebrado com a forte demanda ligada à primeira explosão escolar, consequência do baby-boom de 1946. Passa-se então a recrutar professores também após o ensino secundário (pósbaccalauréat). Essas diferentes trajetórias, no entanto, levam a um e ao mesmo status: o de instituteur.

O corpo docente do ensino médio, no nível superior dessa escala simbólica e com forte legitimidade, é composto pelos agrégés, título que existe desde o final do século XVIII e será institucionalizado por meio do concurso de agrégation a partir de 1845 (Farges, 2017). O recrutamento através da agrégation coexistia com um recrutamento por contrato de répétiteur, uma via mais informal e em função das vagas disponíveis, sob a responsabilidade de um titular (Prost, 2014). Para os aspirantes à profissão docente, tais vagas eram uma maneira de começar, enquanto se cursava a licence disciplinar. A formação universitária, para a qual alguns recebem uma bolsa de estudos, é uma formação sobretudo acadêmica/ disciplinar, com alguns elementos breves de formação pedagógica, sob a forma de um estágio de observação bem como de aulas magistrais.

Os agrégés são majoritários no nível secundário até o período após a Segunda Guerra Mundial, mas coabitam com licenciés (titulares de um diploma universitário) e bacheliers (titulares de um baccalauréat, diploma obtido no final de estudos secundários), que têm a possibilidade de ser confirmados por titularização em seus cargos. Com a primeira explosão escolar em meados do século XX e uma forte demanda por professores do ensino secundário, foi criado o Certificado de Aptidão para Professores do Ensino Médio (CAPES), concurso disciplinar aberto a licenciés, que vem institucionalizar o status de certifiés. Os agrégés se tornam, então, minoritários e os certifiés, majoritários. As oscilações na demanda educacional, em função das oscilações demográficas, são compensadas por um grupo de professores contratados ou por charges de cours $^{6}$. Além dessa heterogeneidade em termos de trajetórias e status, há a heterogeneidade entre as disciplinas, entre setores (geral, tecnológico e profissional) e instituições (secundário inferior e secundário superior, profissional, classes preparatórias), a paisagem do secundário é caracterizada por uma grande pluralidade (Farges, 2017).

6 Pagos por horas/aula realizadas. 


\section{A unificação a partir do collège unique: rupturas e continuidades}

A lei Haby (1977) que implementa o collège unique e a organização do sistema de ensino em duas ordens paralelas é abandonada por uma organização unificada. Os termos primário e secundário passam, então, a designar duas fases sucessivas da escolarização: o primário inclui a maternelle (3 anos) e l'école élémentaire (5 anos) e o secundário inclui o collège (4 anos) e o lycée (3 anos). A implementação da collège unique dá início à segunda explosão escolar (Chauvel, 1998; Poullaouec \& Lemêtre, 2009), período em que a instituição educacional passa a acolher todos os seus públicos numa perspectiva de escolaridade longa, incluindo aquele que se destinava anteriormente a uma escolaridade curta, composto pelos non-héritiers (Bourdieu \& Passeron, 1964). Com a unificação, o ideal meritocrático da escola francesa é colocado em questão, tendo em vista o surgimento do fracasso escolar como fenômeno socialmente situado (IsambertJamati,1985). Torna-se então claro que não basta matricular todos os alunos em um mesmo percurso para que as chances sejam redistribuídas (Dubet \& DuruBellat, 2004). Com o objetivo de reequilibrar as desigualdades educacionais são criadas as Zonas de Educação Prioritária (ZEP) em 1981 por Alain Savary.

Como a unificação do sistema afeta a formação de professores? A médio prazo, resulta na criação dos Institutos Universitários de Formação de Professores (IUFM) em 1989, centralizando em uma mesma instituição a formação de todos os professores, de primeiro e segundo graus e tendo, por consequência, uma mudança de status para os docentes do primário: o corpo de instituteurs dá lugar ao dos professeurs des écoles. Este alinhamento estatutário é acompanhado por um alinhamento do número de anos de estudos universitários necessários, de no mínimo três, para o recrutamento de todos os professores, tanto para a Coordenação de Aperfeiçoamento de Pessoal de Nível Superior (CAPES) como para o Concurso de Recrutamento de Professeurs des Écoles (CRPE). Apesar da unificação, diferenças persistem, incluindo a coexistência de dois corpos de professores secundários, certifiés e agrégés, sendo que para os últimos um ano adicional de estudos universitários é necessário antes de poder prestar o concurso de agrégation.

Essas diferenças estatutárias também resultam em diferentes regimes de trabalho: 27 horas de aula para professores do ensino fundamental, 18 horas para os certifiés e 15 horas para os agrégés (que também podem ensinar na universidade). Agrégés são, então, mais bem pagos por menos horas de aula. Outra diferença persiste, a dominância pedagógica da formação para o ensino primário e disciplinar da formação para o ensino secundário (Isambert-Jamati, 1990). 
A unificação institucional não é suficiente para superar tais diferenças históricas e estatutárias.

Com a implementação dos IUFM, a formação se dá em dois anos, além dos três anos iniciais de estudos universitários. O primeiro ano em IUFM, ao final do qual é colocado o concurso, destina-se à preparação ao concurso, através de aulas, e aos estágios supervisionados. Depois de passar no concurso, os alunos se tornam oficialmente funcionários estagiários e, além da formação teórica, têm 12 semanas de estágio em responsabilidade, divididos em três períodos de quatro semanas, durante os quais, os alunos exercem nos três ciclos do primário.

Mais recentemente, com a masterização da formação em 2008, a dimensão pedagógica da formação é abolida, e a formação universitária de 5 anos (bac + 5) torna-se condição suficiente para candidatar aos vários concursos de admissão à profissão docente. A condição de diploma sendo respeitada, depois de passar no concurso, os professores têm a responsabilidade de uma classe em tempo integral, o que apresenta uma ruptura importante com a tradição francesa de um recrutamento prévio à formação profissional (Prost, 2014). Esse período, embora de curta duração, traz a novidade de um aprendizado da profissão através da experiência, no chão de sala de aula. Nesse modelo, uma formação pedagógica anterior à prática docente aparece como supérflua.

Em 2012, são criadas as Escolas Superiores do Professorado e da Educação $\left(\mathrm{ESPE}^{7}\right)$, reintroduzindo uma dimensão pedagógica e profissional à formação e retornando a um formato mais próximo do que era feito anteriormente, através de um mestrado. No final do primeiro ano, durante o qual ocorre uma formação disciplinar e profissional, os alunos se apresentam ao concurso. No $2^{\circ}$ ano, já concursados, os alunos têm o estatuto de funcionários estagiários e, além do mestrado, tem a responsabilidade uma classe a tempo parcial (50\%) ao longo do ano.

A constante desde a criação dos IUFM é o aumento gradual das exigências enfrentadas pelos professores iniciantes. Esse aumento é perceptível no plano acadêmico: maior número de anos de estudo e escrita de uma monografia, inicialmente profissional e depois de pesquisa. Ele também aparece na parte profissional: em vez das 12 semanas de estágio na época da IUFM, os iniciantes agora são responsáveis por uma classe em período parcial durante o ano letivo, em alternância com o tempo de formação. Resulta que muitas vezes eles têm dificuldades reais em lidar com as várias exigências, profissionais e acadêmicas (Broccolichi, Joigneaux \& Mierzejewski, 2018), que pesam sobre eles.

7 Em 2019, as ESPE foram transformadas em INSPE (Institutos Nacionais Superiores do Professorado e da Educação) e uma nova reforma do recrutamento e da formação está em andamento. 


\section{Recrutamento e lotação de professores: atratividade e estratégias de carreira docente}

O recrutamento por concurso é uma constante: novos professores são recrutados anualmente, mesmo se o número de vagas anunciadas variar de um ano para o outro, o que depende das oscilações demográficas (nascimentos e aposentadorias), bem como das políticas educacionais mais ou menos favoráveis ao recrutamento (Farges, 2017). Desde a década de 2000, houve variações significativas no número de vagas abertas por concurso, primeiro com uma grande escassez de postos (principalmente entre 2008 e 2012), seguido por uma política de criação de empregos direcionados em favor do ensino primário (entre $2012 \mathrm{e}$ 2017). Essas variações impactam diretamente na seletividade do concurso, que deve ser considerada também em função do mercado de trabalho (Périer, 2016).

Também persiste a separação organizacional do primário e do secundário, que repercute no recrutamento de professores: local para o ensino primário e nacional para o secundário. No primário, a concomitância dos concursos locais se traduz em uma forte concorrência entre as academias porque os candidatos devem escolher previamente para qual academia eles candidatam. Essa competição, além do jogo de oferta em termos de viveiro de candidatos potenciais e da demanda por vagas, torna as academias desigualmente seletivas. Essa seletividade desigual entre academias se materializa em proporções candidatos/ vagas muito baixas nas academias menos atrativas: no concurso de 2016 ela era de 1,3 para Créteil e Versalhes, 3,9 para Bordeaux e 5 para Clermont-Ferrand (MEN-DEPP, 2017). É por isso que

[...]a crise de recrutamento de professores é localizada e territorial no primário em que se refere especialmente algumas academias « deficitárias » (Amiens, Créteil, Reims, Versalhes), enquanto outras permanecem particularmente atrativas (Bordeaux, Montpellier, Rennes ...). A questão de atratividade toma uma forma mais difusa no ensino secundário, uma vez que afeta várias disciplinas (Périer, 2016, p. 86).

Para superar a dificuldade de recrutamento, excepcionalmente, um concurso adicional foi criado para Créteil a partir de 2015 e também para Versalhes a partir de 2018, o que permite aos candidatos se apresentar também nestas academias menos atrativas. É uma maneira de superar o déficit crônico, ampliando o viveiro de candidatos e aumentando a seletividade. 
A desigual atratividade das academias também está em jogo na escola secundária, já que a lotação inicial dos professores concursados está ligada à classificação no concurso, as academias menos atrativas e, dentro delas, as instituições de ensino menos demandadas são o destino dos últimos colocados do concurso. Esse efeito é mais pronunciado nos grandes centros urbanos, onde há maior densidade da oferta educacional e, portanto, maior competição entre instituições de ensino (Broccolichi, Ben Ayed, Trancart et al., 2010). Assim, as escolas desfavorecidas tendem a ser evitadas pelos professores assim que o tempo de serviço lhes permite fazê-lo, o que causa uma outra forma de segregação escolar, desta vez entre professores, com alta concentração de iniciantes em algumas instituições. Essa concentração de professores com menos experiência nas regiões mais desfavorecidas também se observa no primário.

O déficit de recrutamento por concurso é compensado pelo recrutamento através de contratos, inclusive na escola primária, o que não ocorria anteriormente como um remédio paliativo "preencher o problema das vagas ociosas" (Farges, 2017, p. 51), problema que tradicionalmente dizia respeito principalmente ao $2^{\circ}$ grau (Périer, 2016). Sem surpresa, os professores contratados se encontram com mais frequência em vagas negligenciadas por titulares e estagiários; o uso de contratos é, portanto, mais frequente na educação prioritária (EP). Os contratados podem representar até $9 \%$ dos professores secundários nos municípios mais desfavorecidos, contra apenas 3\% nos municípios mais favorecidos (Maresca \& Poquet, 2003).

Após a aprovação no concurso, é realizado um ano de estágio em responsabilidade, ao final do qual os iniciantes são, na maior parte dos casos, titularizados $^{8}$. Casos de demissão são bastante raros ${ }^{9}$. A vantagem da estabilidade do funcionalismo público leva aqueles que desejam deixar a profissão a pedir um "afastamento não remunerado" ao invés de pedir demissão, o que pode mascarar as saídas. No entanto, há um forte aumento na taxa de demissão de formandos, que triplicou no nível primário ${ }^{10} \mathrm{e}$ duplicou no secundário ${ }^{11}$ num período muito curto, entre os anos letivos de 2012-2013 e 2015-2016 (Carle \& Férat, 2016).

Além disso, um efeito inesperado do aumento do número de anos de estudo é a atratividade da profissão em trajetórias de reconversão profissional e a

8 Acontece que o período de estágio seja prolongado, para alguns devido a avaliação negativa deste último, para os demais devido a um número insuficiente de dias de estágio, por conta, por exemplo, de uma longa licença médica.

9 Segundo Périer (2016), de $0,11 \%$ no secundário e de $0,10 \%$ no primário.

10 De 65 demissões para 6015 estagiários de primário em 2012-2013 para 434 demissões para 13629 estagiários em 2015-2016, um aumento de 1,08\% para 3,18\%.

11 De 120 demissões para 10496 estagiários do secundário em 2012-2013 para 371 demissões para 14963 estagiários em 2015-2016, um aumento de 1,14\% para 2,48\%. 
chegada de pessoas que preenchem a condição de diploma (mestrado ou equivalente $^{12}$ ). Esses estagiários têm uma obrigação de formação, mas não precisam validar um novo mestrado. Em algumas academias, os iniciantes nesse caso de figura são numerosos e mesmo majoritários, como em Créteil. Em 2017-2018, mais de $53 \%$ dos 2402 funcionários estagiários do primário nessa Academia estavam nesta situação ${ }^{13}$. Ainda não há trabalhos sobre a especificidade desse público, nem sobre como eles constroem a profissionalidade. É, sem dúvida, uma pista de pesquisa a ser aprofundada.

Após a titularização, os professores são lotados nas escolas em função de seus pedidos, mas sobretudo a partir de um sistema de ponderação que leva em conta diversos critérios, dentro dos quais o tempo de serviço e a situação familiar (estado civil, filhos ou dependentes). Com uma situação familiar equivalente, os iniciantes são obrigados a preencher as vagas que não interessam a seus colegas mais experientes (Maresca \& Poquet, 2003). A passagem pela EP torna-se uma forma de "trote institucional". Na verdade, no secundário, três Academias recebem quase a metade dos iniciantes: Créteil, Versalhes e Amiens. São justamente as academias metropolitanas com maior concentração de EP (MEN-DEPP, 2013). Disso decorre uma concentração desigual de iniciantes no secundário: 1 iniciante/20 professores em Créteil, 1/22 em Versalhes e 1/30 em Amiens, enquanto que a média nacional é 1/80 (MEN-DEPP, 2013, p. 2). Não é surpreendente que mais da metade dos pedidos de transferência são provenientes dessas mesmas academias; essa lotação não escolhida muitas vezes resulta em estratégia de fuga, um fenômeno forte na região peri-urbana de Paris. Com o aumento do tempo de serviço, as solicitações de transferência de academia tendem a diminuir, provavelmente por razões de organização da vida privada.

A relação entre o tempo de serviço e o tipo de estabelecimento de lotação (prioritário ou não) é uma constante no ensino secundário (Maresca \& Poquet, 2003). Professores mais experientes (com 50 anos ou mais) representam quase metade dos professores nas escolas mais favorecidas (48\%), proporção de apenas $18 \%$ nas escolas mais desfavorecidas. Também encontramos uma proporção significativa de agrégés (43\%), proporção que é apenas de $21 \%$ nas instituições mais desfavorecidas. Estas últimas têm ainda professores mais jovens (13\%), ao passo que há somente 3\% de iniciantes nas escolas favorecidas. Esses dados merecem ser atualizados com uma comparação cruzada dos dois níveis de educação, mas também em relação à oferta privada local, como é o caso de alguns municípios em processo de gentrificação no leste de Paris (Couratier, François \& Poupeau, 2006).

12 Cinco anos de estudos universitários, correspondendo, no sistema LMD, a nível de mestrado. 13 Obtivemos esses dados diretamente da ESPE em questão. 
A "mobilidade horizontal" como estratégia de carreira para os "novos docentes" já havia sido indicada por Rayou \& Van Zanten (2004) e "não se limita aos primeiros anos de carreira", pelo contrário, esta estratégia também é utilizada por professores experientes (Lothaire, Dumay \& Dupriez, 2012, p. 25). No entanto, essa não é uma estratégia utilizada desde o começo por todos os iniciantes. Segundo o relatório Pochard (2008), uma permanência mais demorada em instituições de ensino consideradas "difíceis" parece ser a escolha de alguns jovens professores como "laboratórios para aprender a dominar todas as dimensões da profissão" (p. 36).

Se a dificuldade escolar não é uma especificidade da EP, sua concentração é a principal característica. Entretanto, os iniciantes ainda não criaram um repertório profissional para lidar com ela. Quais são os efeitos da lotação sistemática de iniciantes a instituições "difíceis"? De que maneira o confronto inicial com essa concentração intervém na construção do profissionalidade docente? O exercício em um cenário de desvantagem social pode resultar em uma configuração de profissionalidade específica, incluindo a redefinição de objetivos (Broccolichi \& Roditi, 2014; Mascret, Maiano \& Vors, 2016; Broccolichi, Joigneaux \& Mierzejewski, 2018), nem sempre em sintonia com o sucesso escolar, uma vez que a gestão da disciplina, a dimensão relacional e a socialização ocupam um lugar central em suas práticas. Pode-se perguntar se essa configuração é feita em detrimento ou em benefício do ensino, estritamente falando. Certamente um ou outro, dependendo de como os professores conseguem construir o sentido de suas práticas profissionais e identificar alavancas pertinentes.

Mais importante, a paisagem das instituições caracterizadas como EP é variada, como mostra Isambert-Jamati (1990). Detalhando o que estas instituições implementam em termos de ações de "reforço de aprendizado", "intensificação dos laços sociais no estabelecimento" e ações "baseadas na cooperação com as instâncias locais não-escolares", ela destaca a diversidade que pode caracterizar uma escola em EP e, consequentemente, a diversidade pode significar o trabalho em EP, que não pode ser entendida monoliticamente (Armand \& Gille, 2006; Kherroubi \& Rochex, 2004; Rochex, 2016). De todos os modos, a lotação obrigatória nesses estabelecimentos ao final da formação contribui para uma forte presença de jovens professores no ensino primário, população tanto "cativa" quanto "móvel” (Kherroubi \& Rochex, 2004, p. 156). Esta população, inicialmente cativa, procura com mais frequência obter uma transferência para escolas mais favorecidas, o que contribui para que as escolas mais desfavorecidas sejam marcadas por uma maior rotatividade da equipe, principalmente porque o período em EP lhes dá um bônus para conseguir uma mutação mais rapidamente (idem). No entanto, uma menor taxa de rotatividade das equipes caracteriza os estabelecimentos EP mais bem sucedidos (Moisan \& Simon, 1997). Chauveau (2001) deplora que 
A guetização de algumas das escolas "suburbanas" está combinada com a instabilidade e a fragilidade do pessoal da Educação Nacional ${ }^{14}$. Em alguns collèges, $50 \%$ dos professores mudam a cada ano e pelo menos $70 \%$ solicitam sua transferência; a cada dois ou três anos, a equipe de direção é completamente renovada. Em várias academias, cerca de um em cada cinco collèges ZEP é hoje um collège de "exílio" ou "relegação", isto é, vítima de uma segregação dupla: a do público escolar e a das prestações de ensino. A conjunção destes dois fenômenos - mediocridade da supervisão pedagógica e concentração de alunos desfavorecidos - produz um fracasso escolar massivo... e "violência" (p. 19-20).

A juventude do corpo docente em EP tem também efeitos indesejados: apesar de uma política redistributiva (menor proporção alunos/professores, bônus salariais), a despesa por aluno é mais baixa que a média nacional (Cour des Comptes, 2012) porque o salário dos iniciantes é menor do que o dos professores mais experientes. Além disso, os incentivos salariais, especialmente o bônus por lotação em EP, não suficientes para reverter as estratégias de mobilidade horizontal, como se a carreira fosse pensada para a maioria dos professores como um percurso das escolas mais desfavorecidas às mais favorecidas. Todavia, como muitos querem ser transferidos, esse cativeiro inicial pode resultar em cativeiro a longo prazo e a pesquisa não produz resultados convergentes sobre a forma como essa permanência é construída. Como indicam Kherroubi e Rochex (2004), a estabilidade relativa das equipes nos anos 90 estava ligada para alguns professores a uma postura engajamento profissional, mais ou menos forte (Bautier et al., 1995), às vezes construída após uma lotação obrigada quando ela pode, para outros, criar uma estabilidade "resignada" (Kherroubi \& Rochex, 2004) mais relacionada a razões pessoais e profissionais, onde o custo de uma transferência é não percebido como vantajoso.

\section{Caracterização sociológica dos professores}

A aposentadoria dos baby-boomers ${ }^{15}$ levou a uma forte renovação da população docente nos últimos anos, particularmente no ensino secundário, entre $40 \%$ e 50\% nos anos 2000 (Kherroubi \& Rochex, 2004). A pirâmide etária dos professores do ensino primário e secundário em 2000 indica uma forte presença

14 Rede pública.

15 Geração nascida durante a explosão demográfica após a 2a Guerra Mundial. 
de professores com mais de 50 anos (MEN-DEPP, 2009). Quinze anos depois, essas pirâmides são alteradas para as diferentes categorias de professores, com um inegável rejuvenescimento em pouco tempo (OECD, 2018).

Essa renovação rápida é um ponto importante. Embora seja difícil abordálo de um ponto de vista diacrônico, na ausência de estudos sobre os iniciantes em épocas anteriores, Rayou e Van Zanten (2004) elaboraram um perfil sociológico desses "novos docentes", com a dificuldade para distinguir o que é um efeito de geração (os professores iniciantes hoje são diferentes dos iniciantes de outras épocas?) de um efeito mais especificamente profissional, relacionado ao estágio de carreira (em que medida os professores iniciantes são diferentes dos professores experientes?). Uma nova profissionalidade surge dessa renovação?

De fato, um novo ethos profissional parece emergir, baseado em uma "atitude de auto-experimentação" (Rayou e Van Zanten, 2004) e marcado pela adaptação pragmática de suas práticas ao público, sinal de maior flexibilidade profissional. Não tendo experimentado outra configuração do sistema educacional do que a do colégio único, eles estão menos preocupados com a legitimidade da presença de públicos "difíceis" e mais preocupados sobre como fazer o trabalho. Experiências, incluindo aquelas em EP, são vividas como desafios que permitem se desenvolver profissionalmente. A ligação com o coletivo é percebida como um meio de desenvolvimento profissional e não como pertença.

Estas mesmas tendências aparecem no estudo de Geay (2010), para os "neo-professores", a profissionalidade é construída em torno de uma lógica de valorização da autonomia pessoal através de um maior distanciamento à dimensão institucional. No entanto, o que pode parecer paradoxal, essa lógica de auto-preservação está ligada com o desencanto no encontro com os alunos reais, especialmente por causa do sentimento de impotência face à desigualdade. Essas duas lógicas combinadas, "face a uma instituição de discurso e futuro incerto é o indivíduo ou exercício interpessoal da profissão que parece ser o melhor instrumento de salvação profissional para além de qualquer otimismo mas também na ausência de qualquer pessimismo radical" (p. 18).

A postura ético-política dos "novos docentes" ou dos "neo-professores" é parte de uma abordagem da profissão interpessoal e não coletiva (em seus aspectos corporativistas ou sindicais). A profissão é concebida pelo prisma da realização pessoal, que também prima no relacionamento com os alunos: permitir que todos se realizem. Essa nova ética baseada no individualismo é provavelmente menos suscetível de integrar um olhar sociologizado das dificuldades escolares, uma vez que a perspectiva individualista pulveriza o social.

Apesar da renovação significativa, também existem continuidades. A profissão continua altamente feminizada ( $80 \%$ no ensino primário e $60 \%$ no ensino secundário) (OECD, 2018). É possível identificar tendências importantes na 
morfologia da profissão docente, a começar pela composição sociológica. Tradicionalmente, o recrutamento se dá entre camadas mais populares para os docentes do primário (Cacouault \& Oeuvrard, 1995; Geay, 1999), mas um aburguesamento progressivo é observado ao longo da segunda metade do século XX. Essa ideia foi recentemente contestada por Vallet e Degenne (2000), para quem esse aburguesamento progressivo seria, sobretudo, a consequência de um maior movimento de aburguesamento da população, não sendo uma peculiaridade dos professores.

Mais recentemente, o estudo de Vallet e Degenne (2000) é, por sua vez, contestado por Charles e Cibois (2010), que estabeleceram comparações em um intervalo de tempo mais longo (dos anos 60 aos anos 90) e também detalharam os processos locais. Os autores conseguem mostrar que há de fato um aburguesamento dos professores primários que se acompanha, paradoxalmente, de uma tendência a sua proletarização, ambos os processos estão diretamente relacionados com a diminuição significativa dos professores oriundos das classes médias. O processo seria principalmente uma "desmedianização" dos professores primários. Esses processos não ocorrem na mesma medida nas academias (idem). O aburguesamento é significativamente mais forte em Paris do que em Versalhes ou em Créteil, o que estaria diretamente relacionado com a composição social da população total dessas academias. Na verdade, Créteil e Versalhes estão marcadas pela presença mais pronunciada da EP, o que confirma a hipótese de um recrutamento diferencial em função das academias. Para os autores, é também essencial para re-situar a entrada no ensino primário em uma concepção mais ampla do espaço social, tendo em conta tanto a elevação do nível social e a feminização do ensino primário. Assim,

a transformação morfológica dos professores do ensino primário, a distância crescente entre as características das professoras e as de seus alunos é, provavelmente, um fator que agrava as desigualdades sociais frente à Escola para alunos de camadas populares. Com efeito, a relação cultivada com a cultura escolar mas também o modo de socialização primária dos novos professores, sem dúvida, não os predispõe favoravelmente ao desenvolvimento das capacidades de percepção e análise das dificuldades específicas e estratégias de apropriação do conhecimento dos alunos de origem popular (Charles \& Cibois, 2010, p. 53).

Os autores consideram que as mudanças na morfologia do corpo docente do primário estão vinculadas à rápida difusão de novas pedagogias na escola primária (educação infantil e elementar), pedagogias caracterizadas como invisíveis por Bernstein (1975/2007) e particularmente inalcançáveis pelos alunos 
menos familiarizados com a cultura e os códigos escolares, por causa de sua origem social. O aumento da distância social entre a profissão docente e os alunos, especialmente em EP, poderia ser considerado como sendo um obstáculo à democratização escolar. Desse modo, invertendo o raciocínio, a proletarização do corpo docente em determinadas Academias poderia favorecer, por um maior conhecimento do contexto e uma maior proximidade cultural, o sucesso de alunos de meios desfavorecidos, a condição que este trabalho de tradução das expectativas da escola seja realizado pelos professores. Essa hipótese, sem dúvida otimista, mereceria ser aprofundada.

Em um estudo sobre a morfologia de professores secundários junto a estagiários, Lazuech (2001) confirma a feminização de futuros professores, bem como a sua experiência escolar anterior bem-sucedida. No entanto, ele aponta uma maior dispersão de sua origem social, uma parte significativa deles provém das camadas populares. Quando esse é o caso, eles são mais frequentemente homens e entram na profissão tardiamente, via posições mais precárias, confirmadas em seguida pela aprovação no concurso. Outra característica desses estagiários de origem popular é de eles terem "alunos com um desempenho inferior" (p. 107) ao de seus pares. Parecem ser assim configuradas trajetórias alternativas de entrada na profissão marcadas menos pela vocação do que pela "necessidade". Experiências profissionais mais precárias contribuem para uma escolha tardia, mais racional e provavelmente menos idealizada do trabalho.

Assim se distinguem dois grupos (Lazuech \& Guibert, 2007): "herdeiros", antigos ótimos estudantes, de origem mais burguesa, que chegam no trabalho docente por amor a uma disciplina e "oblats ${ }^{16}$ " de origem mais popular e tendo tido uma escolaridade menos bem-sucedida que a dos herdeiros. Para os "oblats", a entrada na profissão configura uma promoção social, razão pela qual eles se sentem em dívida com a instituição escolar; além disso, ela é vivida menos como vocação e mais como missão. Essas diferenças refletem-se na maneira como percebem a profissão. "Herdeiros" e "oblats" são diferentes em sua maneira de pensar a escola. Se 75\% dos professores "herdeiros" acham que eles deveriam colocar os alunos no centro do sistema de ensino, essa visão é defendida por $90 \%$ dos "oblats". Ademais, $41 \%$ dos professores do primeiro grupo se definem como educadores, enquanto $84 \%$ do segundo se definem assim. Seria provavelmente oportuno examinar em que medida o compromisso dos "oblats" com

16 Os "oblats" são laicos que aceitam de se conformar às exigências da vida em uma congregação católica, sem para tanto fazer os votos religiosos, em troca da proteção e principalmente de educação no caso de crianças, em uma espécie de ordem secular. Os autores utilizam o termo para reforçar a proximidade desse grupo com a escola, a quem são devedores pela educação recebida, sem contudo compartilhar totalmente os códigos culturais. 
a missão educativa, bem como a importância dada à dimensão relacional da relação pedagógica promove ou, pelo contrário, impede ou atrapalha, a função transmissiva do trabalho docente. Grupos semelhantes emergem do estudo de Léger e Tripier (1986, apud Kherroubi \& Rochex, 2004), para quem

as representações e práticas são, assim, amplamente estruturadas pelas origens sociais e afiliações ideológicas dos professores (filiação sindical, filiação política). E, de fato, a partir do critério de mobilidade, emergem três tipos de professores: os "engajados locais", os "notáveis resignados" [...] e os "ambiciosos por outros lugares", que têm a intenção de solicitar a sua transferência para outro local. O primeiro grupo, o de "professores engajados localmente", inclui mais homens, professores de origem popular e membros de sindicatos do que os outros. O segundo, de "resignados notáveis", é um grupo mais feminizado, de origem social intermediária, pouco sindicalizado. Os que vão embora são jovens professores com menos de trinta anos que têm uma imagem negativa do bairro, baixo ativismo e uma distância maior com a cultura popular (p. 162-163).

Na mesma linha, outro elemento a ser levado em consideração é a chegada à profissão de pessoas de origem imigrante. Para isso, com base em uma pesquisa com estudantes da então IUFM na Academia de Créteil, Charles (2006) conclui que a educação, no ensino primário ou secundário, é uma forma de ascender socialmente para os estudantes e em particular para as estudantes, de origem imigrante (Europa do Sul e Norte da África). Mantendo uma percepção positiva de sua própria escolaridade, elas ingressam na profissão docente quando certas condições sociais são satisfeitas: o sucesso acadêmico, o apoio moral da família e a entrada no mundo educativo pelas margens por meio de experiências profissionais para-educacionais, por exemplo, como animador de colônias de férias, auxiliares de coordenação ou assistentes de educação.

Além de ser uma maneira de financiar os estudos, que não é insignificante dado o aumento do número de anos de estudo necessários para se candidatar ao concurso, essa integração profissional pelas margens como "socialização antecipatória" (Charles, 2006, p. 33), permite passar a conceber o serviço público como um horizonte possível, particularmente na qualidade de professor da escola pública. A presença da população oriunda da imigração é inversamente proporcional à legitimidade social do corpo docente: a proporção de professores cujas famílias vêm do norte da África é maior no corpo docente primário, em comparação com a proporção que eles representam na população ativa; no ensino secundário eles estão mais presentes nos setores técnico e profissional, que são igualmente menos 
valorizados socialmente. Essa diversidade tende a aumentar com a chegada significativa de professores em reconversão profissional (Périer, 2004), mas ainda não há muitas pesquisas sobre este assunto (Berger \& D'Ascoli, 2011), provavelmente por causa das metodologias de coleta de dados, muitas vezes realizada junto a estudantes universitários que aspiram pelo trabalho docente. Justamente, aqueles que chegam tardiamente na profissão, em reconversão, não chegam por esses canais.

Esses diferentes trabalhos indicam uma importante diversidade social e cultural, particularmente marcada nos contextos desfavorecidos. Alguns pontos permanecem pouco trabalhados nas pesquisas atuais, principalmente no tocante à caracterização sociológica de professores contratados (e não concursados), de primeiro e segundo graus. Há também poucos trabalhos sobre professores da rede privada.

\section{Considerações finais}

Se a questão da importante renovação do corpo docente nos últimos anos tem sido tratada com a ajuda da categoria de "novos professores" (Rayou \& Van Zanten, 2004), em contexto desfavorecido, o termo adquire contornos específicos. Por um lado, há uma proporção maior de professores iniciantes ou inexperientes; por outro lado, o corpo docente é mais proletarizado, enquanto ele aparece como oriundo de classes favorecidas em outros contextos. Essa maior diversidade cultural e social e essas diferentes trajetórias de entrada na profissão se traduzem em diferentes representações? De que maneira as trajetórias profissionais específicas dos professores que trabalham com os públicos mais desfavorecidos contribuem para moldar a relação com a profissão e a prática profissional? Elas são portadoras de novas identidades profissionais ou um novo ethos profissional, específico aos contextos de EP? Quais são as implicações em termos de formação inicial e contínua? Qual implicação de suas práticas em termos de democratização? A questão principal é de saber em que medida isso se traduz em maior democratização qualitativa da escola (Bonnéry, 2007), pensada em termos de acesso ao conhecimento e não somente em termos de inclusão escolar. São perguntas que cabe à pesquisa fazer diante dessa dispersão de um corpo profissional que, à primeira vista, poderia parecer homogêneo.

A partir dessa revisão de literatura, surge a ideia de uma composição social diferenciada de professores em EP, resultante da combinação de diferentes camadas de políticas educacionais. Essa heterogeneidade pode contribuir para o enfraquecimento de uma instituição que se apresenta como única, homogênea. Embora seja precipitado concluir que características específicas da composição 
da profissão docente em determinados contextos contribuem para o aumento das desigualdades educacionais, em que o objetivo era, ao contrário, de reduzi-las, pode-se dizer, no entanto, que essa configuração merece atenção específica porque participa de um conjunto complexo de relações que as políticas educacionais devem levar em conta. Torna-se necessário tratar da questão da atratividade da profissão em EP e, mais amplamente, questionar o que a instituição coloca em práticas para acompanhar seus professores na luta eficaz contra as desigualdades. Essas questões são ainda mais centrais em um novo período de reforma do sistema escolar francês e de formação de professores, o terceiro em uma década. Tanta instabilidade, por razões de alternância governamental, pode ter efeitos sobre o trabalho docente e sobre o aprendizado dos alunos.

\section{REFERENCIAS}

ARMAND, A., \& GILLE, B. (2006). La contribution de l'éducation prioritaire à l'égalité des chances des élèves. Rapport au ministre de l'Éducation nationale, de l'Enseignement supérieur et de la Recherche, IGEN et IGAEN. Paris : MENESR.

BAUTIER É., et al. (1995). Travailler en banlieue: la culture de la professionnalité. Paris: L'Harmattan.

BERGER, J.-L., \& D'ASCOLI, Y. (2011). Les motivations à devenir enseignant: revue de la question chez les enseignants de première et deuxième carrière. Revue française de pédagogie. Recherches en éducation, n. 175 (juin): 113-46. https://doi.org/10.4000/ rfp.3113

BERNSTEIN, B. (1975/2007). Classe et pédagogies: visibles et invisibles. In: Deauvieau, J., \& Terrail, J.-P. (2007) Les sociologues, l'école et la transmission des savoirs. Paris, La Dispute.

BONNÉRY, S. (2007). Comprendre l'échec scolaire. Élèves en difficultés et dispositifs pédagogiques. Paris, La Dispute.

BOURDIEU, P., \& PASSERON, J.-C. (1964). Les Héritiers. Les étudiants et la culture. Paris, Minuit, coll. « Le sens commun ».

BROCCOLICHI, S., Ben Ayed, Ch., Trancart, D., et al. (2010). École: les pièges de la concurrence. Comprendre le déclin de l'école française. Paris, La Découverte.

BROCCOLICHI, S., Joigneaux, Ch., \& Mierzejewski, S. (2018). Le parcours $d u$ débutant - enquêtes sur les premières années d'enseignement à l'école primaire. Arras, Artois Presses Universitaires. 
BROCCOLICHI, S., \& RODITI, É. (2014). Analyses didactique et sociologique d'une pratique enseignante. Revue française de pédagogie. Recherches en éducation, n. 188 (septembre): 39-50. https://doi.org/10.4000/rfp.4539

CACOUAUlT, M., \& OeUVRARD, F. (1995). Sociologie de l'éducation. Paris, La Découverte.

CARLE, J.-C., \& FÉRAT, F. (2016). Avis présenté au nom de la commission de la culture, de l'éducation et de la communication sur le projet de loi de finances pour 2017, adopté par l'Assemblée nationale. Tome III, enseignement scolaire. Repéré à https://www.senat. fr/rap/a16-144-3/a16-144-31.pdf. Consulté le 22 février 2018.

CHARLES, F. (2006). L'enseignement: une chance de mobilité sociale pour les jeunes issus des immigrations? Formation emploi. Revue française de sciences sociales, n. 94 (avril): 59-72.

CHARLES, F., \& CIBOIS, P. (2010). L'évolution de l'origine sociale des enseignants du primaire sur la longue durée: retour sur une question controversée. Sociétés contemporaines, n. 77 (mars): 31-55. https://doi.org/10.3917/soco.077.0031

CHAUVEL, L. (1998). La seconde explosion scolaire: diffusion des diplômes, structure sociale et valeur des titres. Revue de l'OFCE, 66 (1): 5-36. https://doi.org/10.3406/ ofce.1998.1507

CHAUVEAU, G. (2001). La réussite scolaire dans les ZEP. Education \& Formations, n. 61-octobre-décembre 2001, L'éducation prioritaire.

COUR DE COMPTES (2012). Égalité des chances et répartition des moyens dans l'enseignement scolaire. Référé, Paris.

COURATIER, E., FRANÇOIS, J.-C., \& POUPEAU, F. (2006). La différenciation sociospatiale des circuits de scolarisation. Enquête sur les pratiques de placement scolaire en contexte de gentrification. Regards sociologiques, n. 31, 2006, pp. 55-90. Repéré à http://www.regards-sociologiques.com/wp-content/uploads/rs_31_2006_4_couratier_ francois_poupeau.pdf. Consulté le 18 avril 2018.

DUBET, F., \& DURU-BELLAT, M. (2004). Qu'est-ce qu'une école juste? Revue française de pédagogie, 146 (1): 105-14. https://doi.org/10.3406/rfp.2004.3099

FARGES, G. (2017). Les mondes enseignants. Paris, PUF.

FONS, J.-Ph., \& MEYER, J.-L. (2005). Les logiques de gestion de l'emploi public enseignant dans trois pays européens. Formation Emploi, n. 92 (1): 5-19.

GEAY, B. (1999) Profession: instituteurs. Mémoire politique et action syndicale. Paris, Seuil. GEAY, B. (2010). Les néo-enseignants face à l'utilitarisme. Actes de la recherche en sciences sociales, n. 184 (août): 72-89. https://doi.org/10.3917/arss.184.0072 
ISAMBERT-JAMATI, V. (1985). Quelques rappels de l'émergence de l'échec scolaire comme «problème social» dans les milieux pédagogiques français. In : Plaisance, E. (Dir.). L'échec scolaire: nouveaux débats, nouvelles approches sociologiques. Paris, Ed. du CNRS, pp. 155-163.

ISAMBERT-JAMATI, V. (1990). Les choix éducatifs dans les zones prioritaires. Revue française de sociologie, 1990, 31-1. pp. 75-100. Repéré à http://www.persee.fr/doc/ rfsoc_0035-2969_1990_num_31_1_1080. Consulté le 18 avril 2018.

KHERROUBI, M., \& ROCHEX, J.-Y. (2004). La recherche en éducation et les ZEP en France. 2. Apprentissages et exercice professionnel en ZEP: résultats, analyses, interprétations. Revue française de pédagogie, 146 (1): 115-90. https://doi.org/10.3406/ rfp.2004.3101 .

LAZUECH, G. (2001). Faire ses classes: les enseignants du secondaire dans leur premier poste. Recherche \& Formation, n. 37. Les emplois-jeunes: entre emploi, formation et professionnalisation, 105-121. Repéré à http://www.persee.fr/doc/ refor_0988-1824_2001_num_37_1_1715. Consulté le 20 avril 2018.

LAZUECH, G., \& GUIBERT, P. (2007). Parcours d'insertion professionnelle des enseignants du secondaire. Actes du Congrès. Actualité de la Recherche en Education et en Formation, Strasbourg 2007. Repéré à http://www.congresintaref.org/actes_pdf/ AREF2007_Lazuech_gilles_GUIBERT_PASCAL_258.pdf. Consulté le 23 février 2018.

LANG, V. (1999). La professionnalisation des enseignants - Sens et enjeux d'une politique institutionnelle. Paris, Puf.

LOTHAIRE, S., DUMAY, X., \& DUPRIEZ, V. (2012). Pourquoi les enseignants quittent-ils leur école? Revue de la littérature scientifique relative au turnover des enseignants. Revue française de pédagogie. Recherches en éducation, $\mathrm{n}$. 181 (décembre): 99-126. https://doi.org/10.4000/rfp.3931

MARESCA, B. \& POQUET, G. (2003). «Les ségrégations scolaires minent le collège unique ». Crédoc, consommation et modes de vie. N. 165, juin 2003

MASCRET, N., MAIANO, N., \& VORS, O. (2016). Buts motivationnels d'accomplissement des enseignants: l'influence de l'appartenance à un établissement «difficile» et de l'ancienneté. Revue française de pédagogie, n. 194: 29-46.

MEN-DEPP (2009). Les départs en retraite des personnels de l'Éducation nationale entre 2000 et 2007. Note d'information 09-17. Repéré à http://media.education.gouv.fr/ file/2009/71/1/NI0917_61711.pdf. Consultée le 21 février 2018.

MEN-DEPP (2013). L'attractivité des académies pour les enseignants du second degré public en 2012. Note d'information. Repéré à http://cache.media.education.gouv.fr/ file/2013/82/4/DEPP_NI_2013_21_attractivite_academies_enseignants_second_degre_ public_2012_272824.pdf. Consulté le 18 avril 2018. 
MEN-DEPP (2017). Concours de professeurs des écoles dans l'enseignement public - Session 2016. Note d'information. Repéré à http://cache.media.education.gouv.fr/ file/2017/80/0/NI-EN-13-2017_779800.pdf. Consulté le 18 avril 2018.

MOISAN, C., \& SIMON, J. (1997). Les Déterminants de la réussite scolaire en zone d'éducation prioritaire. Rapport pour le ministère de l'Education Nationale. Repéré à http:/www.ladocumentationfrancaise.fr/var/storage/rapports-publics/984001171.pdf. Consulté le 22 février 2018.

MOUGNiOTTE, A. (1997). L'École de la République. Revue française de pédagogie, n. 118, 1997. pp. 71-79.

OCDE (2018). Panorama de l'éducation: répartition des personnels de l'éducation par âge. Statistiques de l'OCDE sur l'éducation (database). http://dx.doi.org/10.1787/86d0d5cf-fr PÉRIER, P. (2004). Une crise des vocations? Accès au métier et socialisation professionnelle des enseignants du secondaire. Revue française de pédagogie, n. 147, p. 79-90.

PÉRIER, P. (2016). Rapport-attractivite-metier-enseignant.pdf. CNESCO. Repéré à http://www.cnesco.fr/wp-content/uploads/2016/11/161107-Rapport-attractivite-metierenseignant.pdf. Consulté le 22 février 2018.

POCHARD, M. (2008). Livre vert sur l'évolution du métier d'enseignant. Rapport au Minsitre de l'Éducation nationale, Prais, La Documentation française. Repéré à http:// www.ladocumentationfrancaise.fr/rapports-publics/084000061/index.shtml. Consulté le 22 février 2018.

POULLAOUEC, T., \& LEMÊTRE, C. (2009). Retours sur la seconde explosion scolaire. Revue française de pédagogie, 167, avril-juin 2009, mis en ligne le 01 juin 2013. Repéré à http://journals.openedition.org/rfp/1243. Consulté le 18 avril 2018. DOI: 10.4000/rfp.1243 PROST, A. (dir.) (2014). La formation des maîtres de 1940 à 2010. Rennes, PUR.

RAYOU, P., \& VAN ZANTEN, A. (2004). Enquête sur les nouveaux enseignants. Changeront-ils l'école? Paris, Bayard.

ROCHEX, J.-Y. (2016). Faut-il crier haro sur 1'éducation prioritaire? Analyses et controverses sur une politique incertaine. Revue française de pédagogie, n. 194, 91-108.

VALLET, L.-A. \& DEGENNE, A. (2000). L'origine sociale des enseignants par sexe et niveau d'enseignement. Éducation \& formations, n. 56 - avril-juin. Repéré à http:// media.education.gouv.fr/file/56/69/4/3_25694.pdf. Consulté le 21 février 2018.

Texto recebido em 09/08/2019.

Texto aprovado em $27 / 10 / 2019$. 